American Journal of Applied Sciences 6 (1): 130-132, 2009

ISSN 1546-9239

(C) 2009 Science Publications

\title{
Prevalence and Correlates of PTSD among High School Students After the Earthquake Disaster in the City of Bam, Iran
}

\author{
${ }^{1,2}$ Hassan Ziaaddini, ${ }^{1,2}$ Nouzar Nakhaee, ${ }^{2}$ Kolsoom Behzadi \\ ${ }^{1}$ Kerman Neuroscience Research Center \\ ${ }^{2}$ Kerman University of Medical Sciences, Kerman, Iran
}

\begin{abstract}
Earthquake and its consequences have become recognized as a growing health problem in recent years in developing countries. On 26 December, 2003 at 5.26 Am, the town of Bam in the south eastern part of Iran suffered an earthquake of 6.3 on the Richter scale, killing more than 26000 people. This study was aimed to investigate the prevalence of PTSD and its correlates among high school students in Bam. This cross sectional survey was conducted 10 months after earthquake on all 466 high school students of Bam who remained in the City after the earthquake. Data were collected by a selfadministered questionnaire. The prevalence of PTSD was $66.7 \%$. About $70 \%$ of subjects showed some degree of depression. Girls and those who lost first degree relatives were more likely to suffer from PTSD. So these high risk individuals would need special attention and particular support.
\end{abstract}

Key words: Disaster, mental health, epidemiology, adolescents, Iran

\section{INTRODUCTION}

Earthquake and its consequences present a major public health problem. Like other natural disasters, often without warning, they strike quickly, and are uncontrollable, affecting large population and leaving injury, death, and destruction subsequently. After earth quick, with the loss of loved ones and livelihood, survivors are at increased risk for experiencing psychological distress, including posttraumatic stress disorders (PTSD).The prevalence of PTSD reported in victim of earth quake trauma ranges from $13-95 \%{ }^{[1]}$.

Age may impact the course of the disorders, with elderly subjects having been found to show a significant decrease in posttraumatic symptoms that may be due to lower psychological stress and successful coping in previous disasters experiences ${ }^{[2]}$. Children and adolescents because of their developmental status are more emotionally vulnerable to the devastating effects of a disaster ${ }^{[3]}$. Not only there is a high rate of sever to mild PTSD symptoms in the earth quick exposed children and adolescents but a substantial proportion of them are compatible with the criteria for depression ${ }^{[3]}$.

On 26 December, 2003 at 5.26 Am, an earthquake with a magnitude of 6.3 on the Richter scale struck Bam a city located in Southern Iran, while much of the population were asleep. At least 26000 people were killed during the earth quake and 30000 injuries were reported officially. Also more than 100000 people almost became homeless. According to the Director of the Centre for Humanitarian Psychology In spite of the fact that 6.6 does not seem to be a large earthquake, it killed so many people because it occurred in a city built of adobe ${ }^{[4]}$. This research was conducted to investigate the prevalence of PTSD and its correlates among high school students in Bam.

\section{MATERIALS AND METHODS}

This cross sectional survey was conducted 10 months after earthquake on all 466 high school students of Bam who remained in the City after the earthquake. Data was colleted by a self-administered questionnaire consisting a batteries of questions in three parts after obtaining informed consent: (1) Demographic data including age, educational level, the person's relationship to victims, and the number of relatives lost in the earthquake; (2) Structured PTSD questionnaire according to DSM IV-TR; (3) The Davidson trauma Scale (DTS) a 17 item scale to determine the severity of PTSD symptoms. Each item was rated on 5-point frequency $(0=$ not at all to $4=$ every day $)$ and severity scales $(0=$ not at all distressing to $4=$ extremely distressing). The DTS yields a frequency score (ranging from 0 to 68), severity score (ranging from 0 to 68), and total score (ranging from 0 to 136). A cut off of $\geq 44$ was considered $^{[4]}$. (4) The Beck Depression inventory (BDI), a 21 item self report instrument which is used to

Corresponding Author: Hassan Ziaaddini, Shahid Beheshti Hospital, Neuroscience Research Center, Kerman University of Medical Sciences, Kerman, Iran Tel: +983412111010 
the severity of depression (minimal, mild. moderate) .Each item was rated from 0 to 3 with the maximum possible scale being 63 . Evidence of the reliability and validity of DTS $^{[4]}$ and Beck depression inventory ${ }^{[5]}$ were previously established. Using multivariate logistic regression the association between socio-demographic variable and PTSD were analyzed. The HosmerLemeshow test was used to assess model fit. Statistical analyses were performed using SPSS V.14.

\section{RESULTS AND DISCUSSION}

All of the 466 students completed the questionnaires, of them $60.7 \%$ were female (Table 1). The mean $( \pm \mathrm{SD})$ age of the participants were $15.9( \pm 1)$. According to DSM-IV-TR criteria 311 students $(66.7 \%)$ met the criteria for PTSD. As shown in Table 2 the prevalence of depression among high school students was $70.4 \%(\mathrm{n}=327)$. The frequency of subjects answering yes and the mean score for DTS Items is shown in Table 3.

The final results of the multivariate logistic regressions are shown in Table 4. The highest odds of PTSD was associates with female sex (OR: 2.9, 95\% CI: 1.9-4.5). Those confronted with dead bodies were more likely to express PTSD (OR: 1.9, 95\% CI: 1.2-3.2).

The prevalence of PTSD was $66.7 \%$ which is remarkable in comparison to studies elsewhere ${ }^{[6]}$. It was comparable to studies done after large disasters such as tsunami ${ }^{[7]}$. The differences between these numbers may be due to the different methodologies between surveys and the difference between the nature and severity of the disaster. The severity of trauma in this study may be to some extent, due to the time of earthquake, when the most people were asleep. Concentration difficulties and upsetting by reminders were the two most frequently reported symptoms (Table 3), which was compatible with the findings of Yang et al. ${ }^{[8]}$.

Table 1: Frequency distribution of study participations according to selected characteristics $(n=466)$

\begin{tabular}{lll}
\hline Characteristic & No. & $(\%)$ \\
\hline Sex & 283 & \\
Female & 183 & 60.7 \\
Male & & 39.3 \\
High school grade & 162 & 34.7 \\
9 & 88 & 19.0 \\
10 & 150 & 32.2 \\
11 & 66 & 14.1 \\
12 & & \\
Death of at least one first degree relative & 364 & 78.1 \\
No & 102 & 21.9 \\
Yes & & \\
Confronting with dead bodies & 110 & 23.6 \\
No & 356 & 76.4 \\
Yes & & \\
Living status & 411 & 88.2 \\
With parents & 51 & 10.9 \\
With relatives & 4 & 0.9 \\
Lonely & & \\
General family income & 218 & 46.8 \\
Low & 168 & 36.1 \\
Mid & 80 & 18.7 \\
High &
\end{tabular}

Table 2: Frequency of depression with respect to scores on the Beck Depression Inventory by severity

\begin{tabular}{lll}
\hline$(\%)$ & No. & Severity of depression \\
\hline 29.6 & 139 & Normal \\
20 & 93 & Mild depression \\
11.4 & 53 & Consultation need with psychiatrist \\
20.7 & 96 & Moderate depression \\
11.6 & 54 & Sever depression \\
6.7 & 31 & Very sever depression \\
100 & 466 & Total \\
\hline
\end{tabular}

Table 3: Percentage of students answering yes and mean severity scores for post traumatic stress events in the previous 7 days

\begin{tabular}{lll}
\hline Statement & $\begin{array}{l}\text { Percent of students } \\
\text { answering yes }\end{array}$ & $\begin{array}{l}\text { Mean } \\
\text { severity score }\end{array}$ \\
\hline Have you painful imaginations in relation to painful event? & 83.2 & 4.2 \\
Have you had painful dreams of events? & 83.2 & 4.0 \\
Have you had feeling the event is repeating ? & 71.8 & 3.7 \\
Have you had serious problem in confronting with reminders? & 91.8 & 4.2 \\
When you remember the event, have you had reactions like sweating, palpitation, and shortness of breath? & 39.1 & 1.7 \\
Have you had avoiding from any thought about event? & 72.7 & 3.5 \\
Have you had avoiding from anything or participating in situation those are remembering the event? & 64.1 & 3.1 \\
Have you had realized that you are not able to remember of important parts of event? & 50.9 & 2.2 \\
Have you had many problems in relation to pleasurable things? & 64.1 & 3.2 \\
Have you had feeling of strangeness or disruption in interpersonal relationship? & 61.4 & 2.9 \\
Have you had being unable to love people? & 70.5 & 3.5 \\
Have you had feeling of shortness of the future? & 27.3 & 3.7 \\
Have you had trouble in getting/continuing the sleep? & 69.5 & 3.4 \\
Have you had being aroused, or suddenly to become angry? & 68.2 & 3.3 \\
Have you had trouble in concentration? & 93.2 & 5.5 \\
Have you had feeling as if you are on the edge of precipice and easily become petrified? & 62.7 & 4.3 \\
Have you had sever restlessness? & & 2.4
\end{tabular}


Table 4: Logistic regression analysis to assess the association between selected characteristics and PTSD occurrence

\begin{tabular}{llll}
\hline Characteristic & Adjusted & \multicolumn{2}{l}{$95 \%$ confidence } \\
& OR & intervals & P \\
\hline Age & 1.03 & $0.07-1.23$ & 0.72 \\
Sex & & & \\
Male & 1 & - & \\
Female & 2.92 & $1.9-4.5$ & 0.001 \\
Loss of first degree lative(s) & 61 & 15 & \\
No & 1 & - & \\
Yes & 1.9 & $1.1-3.3$ & 0.02 \\
Confronting with dead bodies & & \\
No & 1 & - & \\
Yes & 1.9 & $1.2-3.6$ & 0.008 \\
Living status & & & \\
With parents & 1 & -- & \\
Others & 1.2 & $0.6-2.3$ & 0.79 \\
Income & & & \\
Low & 1 & - & \\
Mid & 0.8 & $0.5-1.2$ & 0.27 \\
High & 1.1 & $0.6-2.0$ & 0.72 \\
\hline
\end{tabular}

About $70 \%$ of subjects showed some degree of depression (Table 2). A study conducted on students about two months after the 1999 earthquake in Marmara, Turkey revealed that $71.5 \%$ of the students` scores for depression were below the average based on $\mathrm{BDI}^{[9]}$. It is noteworthy that despite several international and national efforts to control psychiatric morbidity in the post earthquake period, such a high burden of depression in the Bam community warrants a revision of the psychiatric and psychological techniques and interventions.

According to logistic regression analysis age and income were not associated with PTSD (Table 4). Girls were up to three times more likely to suffer from PTSD than boys which is consistent with several other studies $^{[10]}$. In most studies conducted on PTSD in post disaster period, females were significantly more susceptible to serious psychiatric morbidity than males ${ }^{[8-10]}$. It was the most significant associated factor for PTSD. The next most important associated factors were confronting with dead bodies and loss of first degree relative(s) carrying odds ratio of 1.9 (Table 4).

\section{CONCLUSION}

According to the higher proportion of PTSD in females and those who lost first degree relatives through disaster more social support should be provided for these high risk groups considering evidence based techniques.

\section{REFERENCES}

1. Armenian, H.K., M. Morikawa and A.K. Melkonian, 2000. Risk factors for depression in the survivors of the 1988 Earthquake in Armenia. J. Urban Health, 79 (3): 373-382.

2. Ohta, Y., K. Araki and N. Kawasaki, 2003. Psychological distress among evacuees of a volcanic eruption in Japan: A follow-up study. Psychiatry Clin. Neurosci., 57 (1): 105-111.

3. Kolaitis, G., J. Kotsopoulos and J. Tsiantis, 2003. Posttraumatic stress reactions among. Children following the Athens earthquake. Eur. Child Adolesc. Psychiatry, 12: 273-280.

4. Colliard C., 2005. Evaluation of the Tdh Psychosocial Programme of Recreational Centres in Bam, Iran. Centre for Humanitarian Psychology, Geneva, Switzerland.

5. Ghassemzadeh, H., R. Mojtabai and N. Karamghadiri, 2005. Psychometric properties of a Persian-language version of the Beck Depression Inventory-2nd Edn. BDI-II-PERSIAN. Depress. Anxiety, 21(4): 185-192.

6. Bokszczanin, A., 2007. PTSD symptoms in children and adolescents 28 months after a flood: Age and gender differences. J. Trauma. Stress., 20: $347-351$.

7. John, P.B., S. Russell and P.S. Russell, 2007. The prevalence of posttraumatic stress disorder among children and adolescents affected by Tsunami disaster in Tamil Nadu. Disaster Manag. Response, 5: 3-7.

8. Yang, Y.K., T.L., Yeh and C.C., Chen, 2003. Psychiatric morbidity and posttraumatic symptoms among earthquake victims in primary care clinics. Gen. Hosp. Psychiatry, 25(4): 253-261.

9. Vehid, H.E., B. Balyanak and A. Eksi, 2006. Suicide ideation after the 1999 earthquake in Marmara, Turkey. Tohoku J. Exp. Med., 208 (1): 19-24.

10. Aksaray, G., G. Kortan and H. Erkaya, 2006. Gender differences in psychological effect of the August 1999 earthquake in Turkey. Nord. J. Psychiat., 60 (5): 387-391. 